\title{
CIRCADIAN VARIATION IN ACUTE CORONARY SYNDROMES AMONG PATIENTS PRESENTING IN A TERTIARY CARE HOSPITAL IN LAHORE
}

\author{
Zeeshan Ghous, ${ }^{1}$ Nauman Naseer, ${ }^{2}$ Ahmed Hassan ${ }^{3}$
}

\begin{abstract}
Background: One of the most important cause of death is Acute Coronary Syndrome (ACS) throughout the world. Its incidence is also increasing in Pakistan. The phenomenon of circadian rhythm is well known among the patients presenting with ACS. This study has been designed to find out the occurrence of this phenomenon in local population. Most of the ACS patients present in early morning hours making management a challenging task at that period of time if no proper logistics are available. The rationale of this study is to emphasize the importance of logistical preparation for management of ACS patients in light of presentation at off hours due to circadian variations.
\end{abstract}

Objective: To determine the frequency of patients with ACS who fall in various categories of timings of day.

Ghous Z. ${ }^{1}$

Registrar Department of Cardiology

Jinnah Hospital, Lahore

Naseer N. ${ }^{2}$

Associate Professor of Cardiology

University of Health Sciences, Lahore

Hassan A. ${ }^{3}$

Senior Register Department of Cardiology

Jinnah Hospital, Lahore
Methodology: 300 subjects those fulfilling the inclusion and exclusion criteria were studied at the department of Cardiology, Jinnah Hospital Lahore, after obtaining the informed consent, data was collected through the proposed performa by researcher himself. We divided the patients into three groups who presented in 24 hours based on the timing of most recent worst symptoms onset that made the patient come to emergency department i.e., 12 am - 08 am, 08 am $04 \mathrm{pm}$ and $04 \mathrm{pm}-12$ am. Data was entered and analyzed in SPSS ver: 17.0. Frequency tablulation and percentages were calculated for circadian rhythm.

Results: When mean age of the patients was calculated it was $54.66 \pm 12.45$ years that included $30.33 \%$ females and $69.67 \%$ male patients. Most of the patients $44 \%(n=132)$ were in the time interval group of $12 \mathrm{am}-08 \mathrm{am}$. There were $25 \%(\mathrm{n}=75)$ of patients in the time interval group of $08 \mathrm{am}-04 \mathrm{pm}$, and $31 \%$ $(n=93)$ patients were presented in the time interval group of $04 \mathrm{pm}-12 \mathrm{am}$.

Conclusions: This study has shown that circadian variation in Acute Coronary Syndrome also exists in our local population, as most of the patients presented in the time interval of $12 \mathrm{am}-08 \mathrm{am}$.

\section{Introduction}

The presence of circadian clock is a well - established fact. There are a lot of properties and behavior patterns 
that represent themselves in circadian or rhythmic patterns. Supra chiasmatic nuclei $(\mathrm{SCN})$ has a major role in the maintenance of this circadian rhythm. SCN is made up of cluster of nerves that counts almost 10 thousand nerve cells. There is synchronization of the circadian clock to the cycles of light as well as darkness that are present in the external environment. As a consequence, most aspects of metabolism and behavior are under the control of these rhythms. ${ }^{1}$ At a molecular level, in all the studied species, the rhythmic expression of the genes involved originates in the network of interconnected transcriptional and translational feedback loops. ${ }^{2}$ In the early hours of morning there is increased secretion of adenosine diphosphate, epinephrine and thrombin that results in more platelet aggregation. During the early morning hours there is decrease in the levels of Anti thrombin and increase in the levels of fibrinogen, also activity of plasminogen activator inhibitor is also increased.

Acute coronary syndrome which includes acute ST elevation myocardial infarction, NSTEMI and UA has become an epidemic in the developing countries and it is still considered a major problem in the developed world. One of the major killers of mankind is acute myocardial infarction and the reason behind it is that a lot of complications can occur as a result of ACS. Clinically established coronary heart disease itself is associated with an increase in mortality from coronary heart disease by a factor of three to seven, depending on the mode of presentation. ${ }^{3}$ Although it is a wellknown fact that much advances have been made in the field of diagnosis and management of ACS but still it is considered the major problem of both industrialized and developing countries. So it is rightly said that one of the leading cause of death is cardiovascular disease.

The rationale of this study comes from the fact that the guideline oriented management of ACS patient's demands high logistic support and availability of certain equipments (Cath. Lab, Echocardiography, Cardiac surgery backup, financial cover). A circadian rhythm is seen in ACS patients worldwide and more patients fall into the early morning hours when availability of logistics may be difficult. This study is to analyze the presence of same circadian rhythm in ACS patients in the local population. If proven to be present our study will put an emphasis on improvement and providence of logistical support round the clock for proper management of ACS patients specially those presenting in early morning hours.

\section{Materials and Methods}

Study Design: Cross sectional survey.

Setting: Department of cardiology, Jinnah Hospital Lahore.

Duration of Study: Six months from 01-01-2015 to 30-06-2015.

Sampling Technique: Non-probability purposive sampling.

Sample Size: There was sample size of 300 cases. Calculation was made confidence level of $95 \%$ and the margin of error was $5 \%$ and taking expected percentage of patients with ACS who fall in (08:00 am 04:00 pm) category of timing i.e., $22.7 \%$ (least among all).

\section{Inclusion Criteria}

- Age $30-75$ years.

- Either sex.

- Patients with ACS which includes acute ST segment elevation MI, NSTEMI, UA.

\section{Exclusion Criteria}

Patients with the following conditions were excluded because they may have significant effect on the circadian rhythm.

- Patient with renal failure (Creatinine > 3.0 assessed on Laboratory test).

- Patient with advance liver diseases (ALT > 120, AST $>120$, Bilirubin $>1.5$ on Laboratory test).

- Patient with Aortic Dissection assessed on history and echocardiography.

- Unconscious / confused etc. patient that is not able to give history about time of onset.

- Presence of malignant hypertension and secondary cause of hypertension assessed on history and physical examination.

\section{Data Collection}

300 subjects those fulfilling the inclusion and exclusion criteria were studied at the department of Cardiology, Jinnah Hospital Lahore, after obtaining the informed consent. A performa was filled for each patient, designed to mention the patients, demographics and other study variables including the circadian variation of ACS according to time of pain onset. We used the 
patient reported time, when the new/ worsening chest discomfort / angina equivalent began as the onset time for ACS. These patients were then treated in the CCU according to existing management protocols.

\section{Data Analysis}

Data analysis was done on software Statistical package for Social science (SPSS) version 10. Continuous variable like age were presented as mean \pm standard deviations. Categorical variables like gender, frequency of circadian rhythm were presented as frequency and percentages. The frequency of ACS onset was compared among the three groups. The test used to assess the statistical significance of circadian rhythm was Chisquare test. A p-value of $>0.05$ was considered significant.

\section{Results}

There were total 300 patients in the study ranging from 28 to 89 years of age (mean $=54.66 \pm 12.45$ years) (Table 1). $69.67 \%$ of patients were males and $30.33 \%$ patients were females. Mean age of males was $54.8 \pm$ 12.4, while that of females was $53.8 \pm 11.9$ years. According to the mode of presentation, $45 \%$ of patients presented with chest pain, $42.3 \%$ with chest pain and diaphoresis, $9.7 \%$ with hypertension and $3 \%$ with diaphoresis only (Table 2 ). There were $38.7 \%$ patients who presented with ST segment elevation myocardial infarction and $61.3 \%$ patients presented with non ST

Table 1: Age Distribution of Patients.

\begin{tabular}{|l|l|c|}
\hline \multicolumn{2}{|c|}{ Age Distribution of Patients (in years) } \\
\hline \multirow{2}{*}{$\mathrm{N}$} & Valid & 300 \\
\cline { 2 - 3 } & Missing & 0 \\
\hline Mean & 54.66 \\
\hline Median & 53.00 \\
\hline Mode & 66 \\
\hline Standard Deviation & 12.454 \\
\hline Range & 65 \\
\hline Minimum & 28 \\
\hline Maximum & 93 \\
\hline
\end{tabular}

Table 2: Patient Distributions According to Presenting Complaints.

\begin{tabular}{|l|l|c|c|}
\hline & & Frequency & Percent \\
\hline \multirow{4}{*}{ Valid } & Chest Pain & 135 & 45.0 \\
\cline { 2 - 4 } & Diaphoresis & 9 & 3.0 \\
\cline { 2 - 4 } & Hypertension & 29 & 9.7 \\
\cline { 2 - 4 } & Chest Pain and Diaphoresis & 127 & 42.3 \\
\cline { 2 - 4 } & Total & 300 & 100.0 \\
\hline
\end{tabular}

Table 3: Patient Distribution on Basis of ECG Changes.

\begin{tabular}{|c|l|c|c|}
\hline & & Frequency & Percent \\
\hline \multirow{5}{*}{ Valid } & ST Elevation & 116 & 38.7 \\
\cline { 2 - 4 } & $\begin{array}{l}\text { ST Depression + T Wave } \\
\text { inversion }\end{array}$ & 184 & 61.3 \\
\cline { 2 - 4 } & Total & 300 & 100.0 \\
\hline
\end{tabular}

Table 4: Cardiac Biomarker* Variations.

\begin{tabular}{|c|l|c|c|}
\hline & & Frequency & Percent \\
\hline \multirow{5}{*}{ Valid } & Positive(NSTEMI) & 68 & 22.7 \\
\cline { 2 - 4 } & Negative(UA) & 116 & 38.7 \\
\cline { 2 - 4 } & Not performed (STEMI) & 116 & 38.7 \\
\cline { 2 - 4 } & Total & 300 & 100.0 \\
\hline
\end{tabular}

*Troponin is the biomarker used in this study by kit bedside method

segment ACS (Table 3). Troponin T test was performed in the patients who presented with ECG changes of ST depression and $\mathrm{T}$ wave inversion which was positive in $22.7 \%$ (NSTEMI) and negative in $38.7 \%$ (UA) (Table 4).

Regarding timing of ACS onset, most of the patients $(44 \%)$ were in the time interval group of 12 am $08 \mathrm{am}, 25 \%$ of patients were in the time interval group of $08 \mathrm{am}-04 \mathrm{pm}$ and $31 \%$ patients were in the time interval group of $04 \mathrm{pm}-12 \mathrm{am}$. The difference was found statistically significant among three time inter- 
val groups with respect to the frequency of ACS onset. $\left(\mathrm{X}^{2}=16.980 \mathrm{P}=.000\right)$ (Table 5).

Table 5: Circadian Variations for Onset of Acute Coronary Syndrome in Patients.

\begin{tabular}{|c|c|c|c|}
\hline & & Frequency & Percent \\
\hline \multirow{5}{*}{ Valid } & $12.00 \mathrm{am}-08.00 \mathrm{am}$ & 132 & 44.0 \\
\cline { 2 - 4 } & $08.00 \mathrm{am}-04.00 \mathrm{pm}$ & 75 & 25.0 \\
\cline { 2 - 4 } & $04.00 \mathrm{pm}-12.00 \mathrm{am}$ & 93 & 31.0 \\
\cline { 2 - 4 } & Total & 300 & 100.0 \\
\hline
\end{tabular}

\begin{tabular}{|l|c|}
\hline \multicolumn{2}{|c|}{ Test Statistics } \\
\hline & Timing of Onset \\
\hline Chi-Square & $16.980^{* *}$ \\
\hline Df & 2 \\
\hline Asymp. Sig. & .000 \\
\hline
\end{tabular}

$* * 0$ cells $(.0 \%)$ have expected frequencies less than 5 . The minimum expected cell frequency is 100.0.

\section{Discussion}

Presence of circadian clock and its effects on the blood pressure, occurrence of acute coronary syndrome is a well - documented phenomenon. Strong evidence has suggested that there is a circadian periodicity of acute coronary event, with the highest rate between 8:00 A.M. and noon. ${ }^{4}$ Many studies has been done internationally on this phenomenon but there is a lack of local literature that is why we have conducted this study, to assess if this phenomenon exists in our population.

Tanaka A et al, ${ }^{5}$ studied whether circadian exists in the plaque rupture in patients presenting with acute myocardial infarction. IVUS was used to investigate the rupture of plaque. Total number of patients was 174 who underwent IVUS before intervention. On the basis of IVUS two groups were formed, one group was called ruptured group and other group was called non ruptured group. There was increased frequency of patients showing their peak occurrence during 6 am to $12 \mathrm{pm}$ in the rupture group $(\mathrm{p}<0.05)$. In the ruptured group the occurrence of clinical features was found more at rest $(67 \%$ vs. $31 \%, \mathrm{p}<0.01)$ and significantly less after pre infarction angina $(22 \%$ vs. $57 \%$, p < 0.01 ) when it was compared with non-rupture group. A different nocturnal nadir was noted during 12 am to 6 am (as compared to all other groups, $\mathrm{p}<0.05$ ) in the non-rupture group.

Li J et al, ${ }^{6}$ studied the circadian variation in patients who had presentation with acute myocardial infarction and also had Type II diabetes. Total numbers of patients were 1016. Two groups were formed, one was diabetic patients and other was non diabetic patients. Day was divided into equal 6 hours intervals. In diabetic group, number of patients in the first quarter was 38 and in second, third and fourth was 45, 43, 46 respectively (NS). While the corresponding values for the controls were 174, 295, 183, 192 ( $\mathrm{P}<0.01)$. The difference between these two groups was found significant $(\mathrm{P}<0.02)$. They concluded that in type II diabetic patients who present with acute myocardial infarction there is no significant circadian rhythm.

Gopal et al, ${ }^{7}$ studied the circadian variation in the patients who presented with acute myocardial infarction. Total numbers of patients were 220. They found out the incidence of ACS was significantly higher $47.7 \%$ between $12: 00$ am to $8: 00$ am as compared to 08:00 am to 04:00 pm and 04:00 pm to $12: 00 \mathrm{am}$ which was $22.7 \%$ and $29.5 \%$ respectively $(p<0.005)$.

In a study by Khan MS et al, ${ }^{8}$ similar findings were observed. Acute MI was diagnosed on the basis of history and ECG findings in the patients with age more than 76 years. Time interval in which maximum patients presented to the hospital was morning hours and its frequency was 2.8 times more. So it was concluded that circadian rhythm is expressed in the presentation patients of ACS.

Rana JS et al, ${ }^{9}$ studied the presence of circadian variations in the diabetic patients who present with acute myocardial infarction. There were 3882 total patients and duration of study was from august 1989 to September 1996. Twenty four hour duration was divided into six hour intervals and chi square test was used. Prominent morning peak was noted in the patients who did not suffer from diabetes mellitus. Marked attenuation in the pattern of morning peak was noted in the patients who suffered from type 1 and type DM for more than or equal to 5 years. While those patients who suffered from DM with duration less than 5 years, had the same pattern as that of non-diabetic patients.

The results of our study are same as the studies that were conducted earlier in the western countries and are present in the literature. Circadian variations 
are also present in our local population who present with the complaint of acute coronary syndrome. Pathogenesis of this complex diurnal relationship has been explained by several postulated mechanisms. A recent study that was published by Goldberg et al. they have evaluated the complex relationship between the specific time at which the symptoms of acute MI appear and awakening. ${ }^{10}$ According to their observation the increase in the increase in the frequency of symptoms of ACS was five times more in initial first hour after awakening. Another study was done by Peters et $\mathrm{al}^{11}$. They also studied the relationship between the time at which symptoms of acute myocardial infarction appear and time of awakening in the morning. They observed the similar findings as observed in the previous studies.

Circadian rhythm is a well - documented phenomenon. Our study is an extension of most of the previous studies and has confirmed the previous results. In a study by fava $S$ et al, ${ }^{12}$ showed the absence of circadian variation in the onset of acute myocardial infarction in diabetic subjects. Another study that showed the absence of circadian variation in the patients who presented with acute coronary syndromes included the patients that were taking beta blocker therapy as treatment. $^{13}$

There were certain limitations in our study. It was a single center study. Also as total number of patients were 300 that was small study population when compared to international studies. Total time interval of 24 hours was divided into three equal intervals only, in which second peak at the night time ${ }^{14}$ was not evaluated which was evident in some of the studies. Sample size remained small due to limitations of exclusion criteria in which patients with liver disease, renal disease, and aortic dissection were excluded because these disease had their effects on the platelets function that may itself alter the disease pattern. All those patients having silent myocardial infarction were also missed in this study.

\section{Conclusion}

This study has shown that circadian variation of acute coronary syndrome exists in our local population presenting in our tertiary care facility.

\section{References}

1. Bodis J, Koppan M, Boncz I, Kriszbacher I. Time of sunrise and hours with daylight may have an effect on the seasonality and diurnal variation of heart attack. Chin Med J. 2009; 122: 2107-10.

2. Kriszbacher I, Bódis J, Boncz I, Koppan A, Koppan M. The time of sunrise and the number of hours with daylight may influence the diurnal rhythm of acute heart attack mortality. Int J Cardiol. 2010; 140: 118-20.

3. Greenfield S, Billimek J, Pellegrini F. Comorbidity affects the relationship between glycemic control and cardiovascular outcomes in diabetes: a cohort study. Ann Intern Med. 2009; 151: 854-60.

4. Ridker PM, Manson JE, Buring JE, Muller JE, Hennekens $\mathrm{CH}$. Circadian variation of acute myocardial infarction and the effect of low - dose aspirin in a randomized trial of physicians. Circulation, 1990; 82: 897902.

5. Tanaka A, Kawarabayashi T, Fukuda D, Nishibori Y, Sakamoto T, Nishida Y et al. Circadian variation of plaque rupture in acute myocardial infarction. Am J Cardiol. 2004; 93: 1-5.

6. Li J, Hua Q, Pi L, Tan J, Li B. Circadian variation on the onset of acute ST segment elevation myocardial infarction in diabetic subjects. J Cardiovasc Dis Res. 2010; $1: 6$.

7. Gopal M, Boopathy N, Venkatesan R, Jagannathan V. Circadian variation in acute coronary syndromes. Webmedcentral cardiology, 2010; 1: WMC00533.

8. Khan MS, Ahmad SI. Circadian variation - increased morning incidence of acute myocardial infarction in patients with coronary artery disease. J Pak Med Assoc. 2003; 53: 84-7.

9. Rana JS, Mukamal KJ, Morgan JP, Muller JE, Mittleman MA. Circadian variation in the onset of myocardial infarction: effect of duration of diabetes. Diabetes, 2003; 52: 1464-8.

10. Goldberg RJ, Brady P, Muller JE, Chen Z, Groot M, Zonneveld $\mathrm{P}$ et al. Time of onset of acute myocardial infarction. Am J Cardiol. 1990; 66: 140-4.

11. Peters RW, Zoble RG, Liebson PR, Pawaitan Y, Brooks MM, Proschan M. Identification of secondary peak in myocardial infarction onset 11 to 12 hours after awakening: The cardiac arrhythmia suppression trial (CAST) experience. J Am Coll Cardiol. 1993; 22: 998-1003.

12. Fava S, Azzopardi J, Muscat HA, Fenech FF. Absence of circadian variation in the onset of acute myocardial infarction in diabetic subjects. Br Heart J. 1995; 74: $370-2$.

13. Muller JE, Stone PH, Turi ZG, Rutherford JD, Czeisler $\mathrm{CA}$, Parker $\mathrm{C}$ et al. Circadian variation in the frequency of onset of acute myocardial infarction. N Engl J Med. 1985; 313: 1315-2.

14. Kinjo K, Sato H, Sato H, Shiotani I, Kurotobi T, Ohnishi $\mathrm{Y}$ et al. Circadian variation of the onset of acute myocardial infarction in the Osaka area, 1998-9: characterization of morning and nighttime peaks. Jpn Circ J. 2001; 65: 617-20. 